\title{
Reseña bibliográfica: Bragoni, Beatriz. San Martín. Una biografía política del Libertador. Argentina, Edhasa, 2019, 344 pp.
}

Palabras clave: San Martín - Biografía - Política - Trayectoria - Usos del pasado

Keywords: San Martin - Biography - Politics - Career - Uses of the past

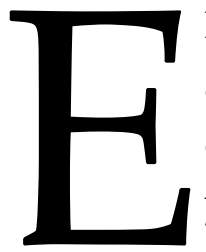

1 libro de Beatriz Bragoni forma parte de una colección de biografías argentinas editadas por el sello editorial Edhasa, en la que son abordadas diferentes figuras de la historia argentina a partir de interrogantes nuevos y complejos, con arreglo a los diversos aportes que ha ido recuperando el género biográfico en el ámbito de la producción e investigación históricas.

He ahí, entonces, que podemos hablar de un género que goza de una vitalidad importante y que se cultiva en sintonía con las exigencias de la producción académica sin menoscabo de una narrativa amena que permite afirmar que se trata de libros destinados a un público curioso cuyo alcance excede al de los estudiosos.

El trabajo de Bragoni contiene cada uno de estos elementos, que juntos componen una obra indispensable para acercarse a una figura que ocupa un lugar indiscutido en el panteón de héroes y próceres que se constituyó a lo largo de dos siglos mediante diferentes operaciones deliberadas y, no pocas veces, de manera contradictoria. Un libro sobre el libertador no implica una novedad en sí misma; sin embargo, sí resultan relevantes las aproximaciones que la autora realiza en torno a su figura. Este libro tiene, por un lado, el mérito de situar a José de San Martín en el contexto general de la crisis del vínculo con el imperio, mientras que, por otro, nos permite acercarnos a un hombre que no tenía ni laureles ni bronce garantizados y que debió experimentar una variada serie de conflictos con los diversos actores que disputaban en el interior del bloque revolucionario en un amplio escenario no desprovisto de tensiones ni contradicciones.

El capítulo primero lleva como título “De la Península al Río de la Plata revolucionario" y permite adentrarnos en la vida de José de San Martín desde sus tempranos inicios en las instituciones reales en la península. Son consignados su bautizo de fuego, su desempeño en las guerras contra las tropas napoleónicas, el mérito alcanzado en la decisiva batalla de Bailén, la desconfianza que en él inspiraran los clamores populares a partir de las agitaciones y revueltas que tuvieron lugar en 
España durante la primera década de $1800 \mathrm{y}$, fundamentalmente, las dificultades que atravesaban los jóvenes militares nacidos en suelo americano para obtener ascensos en los diferentes grados de las fuerzas reales. Pero la experiencia en armas no sería suficiente para explicar el advenimiento de San Martín a la causa revolucionaria: en su formación política e ideológica, tendrá un papel crucial la cada vez más importante sociabilidad en la que se vinculaba, que tenía lugar en ciudades europeas como Cádiz o Londres en las que se encontraban muchos de aquellos jóvenes oficiales americanos. A partir de entonces, decidido a sumarse a la causa americana, parte con rumbo al virreinato en el que había nacido, sin más contactos ni oportunidades en la sociedad rioplatense que los que podría proveerle Carlos María de Alvear.

Ya situado en Mendoza, en el epicentro de esa "Ínsula Cuyana" (tal es el título del segundo capítulo), Bragoni ofrece un interesante abordaje de la situación a la que arribó San Martín: siendo un hombre que no tenía vínculos en la región, resultó una condición indispensable establecer buenas relaciones desde el comienzo de su gestión con los capitulares. También se recupera el importante desafío que debió asumir como gobernador de Cuyo: aquella complicada migración de chilenos refugiados, expulsados por las fuerzas realistas, fuertemente afectada por rencillas internas que comprometían la homogeneidad del bloque revolucionario chileno y que, por lo tanto, amenazaban la centralidad que requería la conducción de su proyecto. Tales facciones estaban lideradas por Bernardo O’Higgins y José Miguel Carrera. Respecto a este último, Bragoni resalta la actitud de San Martín, quien depositó sus sospechas sobre él y sus hermanos, dado que planteaban un desafío a su liderazgo que podía perforar el esquema de poder que tan trabajosamente se propuso desplegar en aquella región.

El capítulo tercero está dedicado a la campaña de Chile. Allí, es posible enumerar las principales dificultades que comportaba la ambiciosa empresa de cruzar los Andes con la finalidad de hacer la guerra. Desde la difícil provisión de los recursos a la complejidad de transportarlos por un paso fronterizo expuesto a variadas inclemencias, pero también, y quizás de manera tan o más fundamental, los desafíos de orden político: por un lado, las fisuras del foco revolucionario chileno que amenazaban con hacer mella en la dirección centralizada; por otro lado, en el orden interno, la tensiones cada vez más manifiestas entre el Litoral y el Directorio, intensificadas luego de la invasión portuguesa a la Banda Oriental. Ante ese escenario de diversos frentes que podían afectar al plan continental de restituir la libertad política en Chile y solidificar la independencia en las Provincias Unidas con miras a avanzar rumbo al norte para hacer la guerra a los realistas en el Perú, la consecución del cruce podía verse afectada por el estallido de una crisis política que operara decisivamente contra la autoridad constituida en el Río de la Plata. Bragoni, entonces, nos presenta a José de San Martín en el terreno de la política, de la deliberación, de la duda y de la acción. Sus cavilaciones en torno a los pasos a seguir ante coyunturas adversas o complicadas, nos revelan una faceta pragmática, aunque consistente con sus convicciones revolucionarias frente a las oscilantes condiciones políticas y a los cambios que 
operaban sobre el apoyo al plan continental. También es recuperada una cuestión relevante vinculada a la lectura que San Martín realizaba sobre su lugar en la revolución: su preocupación ante el juicio de la posteridad, en tanto entendía que sus acciones debían ser contempladas en una perspectiva más amplia, que solamente el devenir de los acontecimientos permitiría justificar. En esos términos juzgó su renuncia a la jefatura del Ejército de los Andes y su convicción de que el siguiente objetivo, luego de Maipú, era avanzar hacia el norte para hacer la guerra en Lima.

La campaña de Perú es el tópico del cuarto capítulo, en el que la destreza narrativa de la autora facilita un relato ameno respecto a uno de los momentos fundamentales del periplo sanmartiniano en el marco de la consolidación del plan continental. Hacia 1820, ante el desacato a las autoridades rioplatenses de intervenir con sus fuerzas en la represión de los movimientos disidentes del Litoral, José de San Martín emprende la marcha hacia Santiago desde donde se pondrá al mando de las fuerzas que partirían rumbo al Perú con la intención de atacar en su interior al foco realista que amenazaba los avances alcanzados en Chile y la integridad misma de la independencia de las Provincias Unidas. Las acciones políticas de San Martín en Lima, la empresa de construcción de consensos a favor de la causa independentista a través de la puesta en marcha de un aparato de propaganda con Bernardo de Monteagudo a la cabeza y la actividad de las sociedades secretas afines resultan elementos claves para dimensionar el esfuerzo de los revolucionarios en el epicentro del realismo en América del Sur. Tan es así, que la asunción del mando político y militar por parte del Libertador en aquellas latitudes se vería fuertemente acompañada de la pompa y el boato propios de una sociedad fuertemente imbricada con las tradicionales jerarquías, el ceremonial y las representaciones coloniales, dando prueba de la comprensión por parte de los actores de la necesidad de adaptarse a las circunstancias del terreno. No obstante, los esfuerzos orientados en miras de consolidar el poder independiente a través de la asunción del Protectorado del Perú y la adopción de un diseño institucional en sintonía con el ideal centralizador y liberal en lo que respecta al reconocimiento de los derechos de los indígenas y la adopción de un régimen comercial decididamente librecambista y la dinámica interna de las relaciones entre los sectores vinculados a la elite limeña impondría límites a las pretensiones sanmartinianas. Así, nuevamente se encontró ante el dilema de abandonar el teatro de las operaciones en virtud de las tensiones surgidas hacia el interior de los núcleos de poder dominantes que con mayor o menor agrado habían gravitado a favor del proyecto emancipador por él defendido, en un territorio en el que esos grupos se habían avenido con reservas a dicha causa. Comprobó así el estado fragmentario de las redes de apoyo locales y emprendió nuevamente una serie de recorridos que lo recondujeron nuevamente a Europa.

El quinto capítulo, "El peregrinaje del guerrero", da cuenta del vasto itinerario seguido por José de San Martín tras separarse del protectorado peruano y abandonar las actividades política y la militar. Buenos Aires, Londres, Marsella, Bruselas, París, Southampton son algunas de las ciudades que constituyen su amplio recorrido y en las 
cuales logró servirse de los vínculos establecidos gracias a las distintas sociedades secretas con las que tenía algún tipo de vinculación. Estas resultaron fundamentales durante este periodo, porque, como bien lo enfatiza la autora, la situación patrimonial del ya viudo y aquejado militar presentaba una serie de dificultades que intentaba sortear con la finalidad de procurar las mejores posibilidades educativas para su hija. No solo las preocupaciones económicas eran el objeto de sus pensamientos, sino también los acontecimientos en el territorio americano. Así, llegaría a la conclusión de que, hacia 1827, su retorno a Buenos Aires podía concretarse en virtud de la caída de Rivadavia y el conflicto abierto con el Brasil, con la intención de retornar a las armas y ofrecer sus servicios a su país. Sin embargo, el curso de los acontecimientos disparados por el fusilamiento de Dorrego en manos de un viejo conocido suyo, Juan Lavalle, lo forzaron a desistir de desembarcar en la capital porteña.

"El Ostracismo Voluntario" es el sexto capítulo, en el que son abordadas las principales acciones del protagonista en su estadía francesa: primero en París, luego en Grand Bourg y, finalmente, en Boulogne-sur-Mer, donde decidió residir a raíz de los acontecimientos de finales de la década del cuarenta. Respecto a aquellos movimientos revolucionarios, Bragoni recupera los resquemores y desconfianzas del libertador frente a las irrupciones populares y a los peligros que significarían para el orden constituido. En esa misma senda, son abordados sus juicios relativos a dos realidades del orden americano sobre las cuales se expresó en términos elogiosos: el Chile de Manuel Bulnes y el sistema instaurado por Juan Manuel de Rosas a lo largo del territorio de la Confederación. De ambos experimentos políticos, San Martín rescató la consolidación, hacia el otro lado de la cordillera, de un sistema republicano liberal en el que identificaba "la preponderancia de la parte más instruida", mientras que verá en el gobernador de Buenos Aires al hombre capaz de restituir el "orden" en el espacio rioplatense luego de los acontecimientos que frustraron su retorno hacia finales de la década del veinte. Se recuperan también, en esta sección, los encuentros que tuvo con algunos de los integrantes de la Generación del 37, con quienes intercambió opiniones y comentarios, en un indicio claro de la significación que su figura iba adquiriendo para aquellos letrados.

Los dos últimos capítulos son hábilmente enlazados por un tópico central: la muerte de José de San Martín y las variadas operaciones construidas al respecto. Por un lado, en el capítulo siete, "El Regreso del Héroe", donde su fallecimiento ocupa un lugar fundamental en relación con las variadas respuestas que tuvo en los diversos puntos sobre los cuales su accionar tuvo impacto. Se destaca especialmente el escenario argentino durante las presidencias que sucedieron a la conformación del Estado nacional a partir de 1862. Así, la repatriación de sus restos hacia 1880 operaría como una acción deliberada e impulsada por parte de una nueva generación de políticos e intelectuales, que vieron, en la significación de su funeral cívico, una posibilidad de clausurar el largo ciclo de violencia política. De esa forma, la construcción de su persona como "el padre de la patria" haría las veces de elemento catalizador de 
sensibilidades patrióticas destinadas a consolidar sentimientos de pertenencia con el Estado nacional, en un país que ya comenzaba a adquirir una fisonomía diferente a partir del influjo migratorio.

Finalmente, "Los usos públicos de San Martín", capítulo octavo y último, aborda diversas interpretaciones construidas en torno al libertador con la finalidad de abonar determinados suelos reivindicativos: desde el clásico trabajo de Ricardo Rojas, pasando revista también a los distintos esfuerzos de la liturgia peronista durante la primera presidencia de Juan Domingo Perón por vincular al líder justicialista con José de San Martín, en un ejemplo claro de uno de los usos políticos de la historia, hasta otras muestras del pasado reciente de la Argentina que son recuperadas en función de sus diversas apelaciones a la figura de San Martín, incluso en el siglo XXI. Este hecho, expresa la vitalidad de su figura y su vigencia en el ámbito de la divulgación aficionada, pero también, de manera saludable, $y$, como lo evidencia este libro, en el campo historiográfico.

Rodrigo Alfredo Ferrero

Universidad Nacional de Córdoba

alfredof2912@gmail.com

Para citar esta reseña:

Ferrero, Rodrigo Alfredo (2021): Reseña bibliográfica, "Bragoni, Beatriz. San Martín. Una biografía política del Libertador. Argentina, Edhasa, 2019, 344 pp." Anuario de la Escuela de Historia Virtual 19, 172-176. 